\title{
CORRIGENDUM The effect of PDE5 inhibition on the erectile function in streptozotocin-induced diabetic rats
}

GJ Ahn, YS Sohn, KK Kang, BO Ahn, JW Kwon, SK Kang, BC Lee and WS Hwang

International Journal of Impotence Research (2006) 18, 576. doi:10.1038/sj.ijir.3901474

Correction to: International Journal of Impotence Research (2005) 17, 134-141. doi: 10.1038/sj. ijir.3901295
Following the publication of this article, the authors found that one of the figures was duplicated. The below Figure 3d is the correct figure.

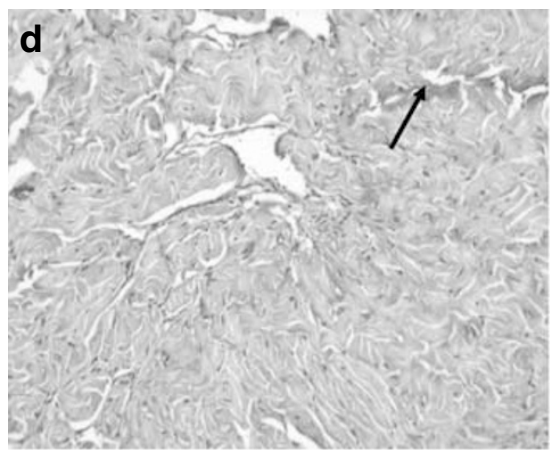

Figure 3 Representative immunohistochemical localization of TGF- $\beta 1$ in the control, diabetic and DA-8159-treated rats $(\times 100)$ ((a) normal control; (b) diabetic control; (c) DA-8159 $5 \mathrm{mg} / \mathrm{kg}$ and (d) DA-8159 20 mg/kg). Arrows indicate positive staining for TGF- $\beta 1$. 